\title{
Self-Assembly of Novel Mesoporous Manganese Oxide Nanostructures and Their Application in Oxidative Decomposition of Formaldehyde
}

\author{
Hongmin Chen, ${ }^{\dagger, \S}$ Junhui He, ${ }^{*, \dagger}$ Changbin Zhang, ${ }^{\ddagger}$ and Hong $\mathrm{He}^{\ddagger}$ \\ Functional Nanomaterials Laboratory and Key Laboratory of Organic Optoelectronic Functional Materials and \\ Molecular Engineering, Technical Institute of Physics and Chemistry, Chinese Academy of Sciences (CAS), \\ Beijing 100080, P.R. China, Graduate University of Chinese Academy of Sciences, Beijing 100049, P.R. China, \\ and State Key Laboratory of Environmental Chemistry and Ecotoxicology, Research Center for \\ Eco-Environmental Sciences, Chinese Academy of Sciences (CAS), Beijing 100085, P.R. China
}

Received: July 31, 2007; In Final Form: September 18, 2007

\begin{abstract}
Monodisperse manganese oxide honeycomb and hollow nanospheres have been prepared facilely at room temperature by varying the molar ratio of $\mathrm{KMnO}_{4}$ and oleic acid. These new nanomaterials were characterized by XRD, SEM, EDS, TEM, and BET measurements. They had robust nanostructures and were stable even after ultrasonic treatment $(40 \mathrm{kHz}, 120 \mathrm{~W})$ for $30 \mathrm{~min}$. A plausible mechanism of the formation of manganese oxide nanostructures was proposed. The manganese oxide nanomaterials showed high catalytic activities for oxidative decomposition of formaldehyde at low temperatures. Complete conversion of formaldehyde to $\mathrm{CO}_{2}$ and $\mathrm{H}_{2} \mathrm{O}$ could be achieved, and harmful byproducts were not detected in effluent gases. The catalytic activity of manganese oxide hollow nanospheres was much higher than that of honeycomb nanospheres, although the surface area of the latter was nearly 2 times as high as that of the former. The mechanism of such morphologydependent catalytic activity was discussed in detail. The catalytic activities of the obtained manganese oxide nanospheres were also significantly higher than those of previously reported manganese oxide octahedral molecular sieve (OMS-2) nanorods, $\mathrm{MnO}_{x}$ powders, and alumina-supported manganese-palladium oxide catalysts. Potential applications and future research efforts were proposed.
\end{abstract}

\section{Introduction}

Controlling the size, shape, and structure of inorganic nanomaterials to search for new properties has become one of the major objectives of nanoscale science and technology, because of their structure-, size-, and shape-dependent characteristics and novel electronic, magnetic, optical, chemical, and mechanical properties that cannot be obtained in their bulk counterparts. ${ }^{1,2}$ Oxides of transition metals, which have different oxidation states and coordination numbers, are especially interesting due to their unique electronic, optical, thermal, photonic, and catalytic properties in different morphologies. ${ }^{3}$ Recently, much attention has been paid to 3D nanostructures, such as $\mathrm{TiO}_{2}, \mathrm{SnO}_{2}, \mathrm{MnO}_{2}$, and $\mathrm{Fe}_{2} \mathrm{O}_{3}$ hollow spheres and other nanostructures. ${ }^{4}$ Among various strategies for controlled synthesis, the "soft chemistry" route, which is based on a solution process, is effective for the synthesis of nanostructured materials with well-controlled shapes, sizes, and structures. ${ }^{5}$

Manganese oxides $\left(\mathrm{MnO}_{2}\right)$ have been extensively studied as a well-known transition-metal oxide, because of their outstanding structural multiformity combined with novel chemical and physical properties and wide applications in catalysis, ion or molecular sieves, molecular adsorption, biosensors, electrode materials in batteries, and energy storage.$^{6-14}$ Different $\mathrm{MnO}_{2}$ morphologies have so far been prepared, including rods, wires,

* To whom correspondence should be addressed. Tel.: +86-10-8254 3535. Fax: +86-10-8254 3535. E-mail: jhhe@mail.ipc.ac.cn.

$\dagger$ Technical Institute of Physics and Chemistry, Chinese Academy of Sciences.

$\doteqdot$ Research Center for Eco-Environmental Sciences, Chinese Academy of Sciences.

$\S$ Graduate University of Chinese Academy of Sciences. tubes, urchin-like microstructures, etc. They were prepared either by oxidizing $\mathrm{Mn}^{2+}$ with oxidants or by reducing $\mathrm{MnO}_{4}^{-}$with reductants. Very recently, Suib and co-workers ${ }^{15}$ prepared cryptomelane-type $\mathrm{MnO}_{2}$ octahedral molecular sieve microspheres (OMS-2) and mesoporous $\gamma-\mathrm{MnO}_{2}$ hollow nanospheres by hydrothermal method. Xie and co-workers ${ }^{16}$ prepared $\beta-\mathrm{MnO}_{2}$ nanorods, urchin-like $\alpha-\mathrm{MnO}_{2}$ microspheres and $\alpha-\mathrm{MnO}_{2}$ hierarchical structures via a homogeneous catalytic route. However, few works were reported on nanostructures of layered $\mathrm{MnO}_{2}$, such as birnessite-type $\mathrm{MnO}_{2}\left(\mathrm{~A}_{x} \mathrm{MnO}_{2}\right.$, where $\mathrm{A}=\mathrm{H}^{+}$or metal cation). $\mathrm{A}_{x} \mathrm{MnO}_{2}$ is a layered structure consisting of edge-sharing $\mathrm{MnO}_{6}$ octahedra with an interlayer spacing of ca. $0.7 \mathrm{~nm} .{ }^{17}$ It can be widely used in applications, such as ionic adsorption, ${ }^{18}$ battery electrodes, ${ }^{19}$ electrochemical and magnetic materials, ${ }^{20,21}$ and oxidative degradation of organic and inorganic contaminations. ${ }^{22}$ Hydrothermal reaction, ${ }^{23}$ solgel process, ${ }^{24}$ reflux method, ${ }^{25}$ and thermal decomposition ${ }^{26}$ have been used to synthesize $\mathrm{MnO}_{2}$ materials of various ordered morphologies. Obtained $\mathrm{MnO}_{2}$ particles, however, were several microns in size and most of the prepared methods needed catalysts, acid or alkaline media, or high temperatures.

Formaldehyde is a major indoor air pollutant and is known to cause irritation to eyes, respiratory tract, and skin even at concentrations of ppm levels. ${ }^{27}$ It exists in isolating materials, furniture, wood, exhaust gases, disinfectants, and tobacco smoke. It is also used as an additive in water-based paints. Currently effective removal of $\mathrm{HCHO}$ is attracting much attention. The catalytic decomposition of $\mathrm{HCHO}$ has been achieved in the temperature range $90 \sim 500{ }^{\circ} \mathrm{C}$. Facile decomposition of $\mathrm{HCHO}$ at low temperature, however, is still a challenge though there are increasing concerns on $\mathrm{HCHO}$ in the indoor environment. 
CHART 1: Synthetic Procedures of $\mathrm{K}_{x} \mathrm{MnO}_{2}$ Honeycomb and Hollow Nanospheres $\left(\mathrm{C}_{\mathrm{KMnO4}}=\right.$ Concentration of $\mathrm{KMnO}_{4}$ ).

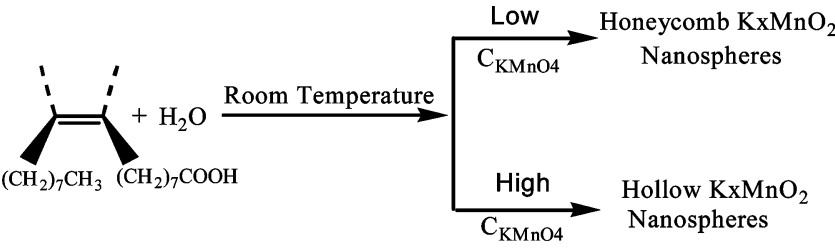

Catalytic oxidation is a promising approach as $\mathrm{HCHO}$ can be oxidized to $\mathrm{CO}_{2}$ over catalysts at lower temperatures than thermal oxidation. ${ }^{28} \mathrm{MnO}_{x}$ powders, $\mathrm{MnO}_{2}$ octahedral molecular sieve (OMS-2) nanorods, and alumina-supported manganesepalladium oxides $\left(\mathrm{Mn}-\mathrm{Pd} / \mathrm{Al}_{2} \mathrm{O}_{3}\right)$ were used as catalysts for decomposition of $\mathrm{HCHO}$, and the latter two catalysts showed high activities at low temperatures. ${ }^{29}$ Very recently, Sinha et al. ${ }^{30}$ reported that mesostructured 2.8 wt $\% \mathrm{Au} / \gamma-\mathrm{MnO}_{2}$ nanoparticle composites could be used for extensive air purification.

In this article, we reported self-assembly of manganese oxide nanoplatelets into novel mesoporous nanostructures and their application in oxidative decomposition of formaldehyde. Complete conversion of $\mathrm{HCHO}$ to $\mathrm{CO}_{2}$ and $\mathrm{H}_{2} \mathrm{O}$ was achieved at low temperatures, and harmful byproducts were not detected in effluent gases. The as-prepared mesoporous nanostructures also showed better catalytic activities for decomposion of $\mathrm{HCHO}$ than other existing $\mathrm{MnO}_{2}$ materials.

\section{Experiments}

$\mathrm{K}_{x} \mathrm{MnO}_{2}$ honeycomb nanospheres and hollow nanospheres were synthesized via a simple soft chemistry route at room temperature, as described in Chart 1.Oleic acid (OA) was oxidized by potassium permanganate $\left(\mathrm{KMnO}_{4}\right)$ in neutral aqueous solution. Such a reaction was also called "Baeyer test for unsaturation". 31

2.1. Materials. Potassium permanganate ( $\geq 99.5 \%)$, oleic acid $(\geq 99.5 \%)$, and ethanol $(\geq 99.7 \%)$ were purchased from Beijing Chemical Reagent Company and used without further purification. Distilled water was used throughout.

2.2. Synthesis of $\mathrm{K}_{x} \mathrm{MnO}_{2}$ Honeycomb Nanosphere. In a typical procedure, $1.0 \mathrm{~g}(6.3 \mathrm{mmol})$ of $\mathrm{KMnO}_{4}$ was dissolved in $500 \mathrm{~mL}$ of distilled water, and the mixture was fleetly stirred for about $30 \mathrm{~min}$. A total of $10.0 \mathrm{~mL}$ of oleic acid was added, and a steady emulsion was formed. After the emulsion was maintained at room temperature for a certain period of time, brown-black products were collected and washed several times with distilled water and alcohol to remove any possible residual reactants. Finally, the products were dried under a vacuum at $60{ }^{\circ} \mathrm{C}$ for $10 \mathrm{~h}$.

2.3. Synthesis of $\mathrm{K}_{x} \mathrm{MnO}_{2}$ Hollow Nanospheres. A total of $2.0 \sim 4.0 \mathrm{~g}(12.6 \sim 25.2 \mathrm{mmol})$ of $\mathrm{KMnO}_{4}$ was dissolved in 200 $\mathrm{mL}$ of distilled water, and the mixture was stirred for about 30 min. A total of $4.0 \mathrm{~mL}$ of oleic acid was added, and a steady emulsion was formed. After the emulsion was maintained at room temperature for a certain period of time, brown-black products were collected and washed several times with distilled water and alcohol to remove any possible residual reactants. Finally, the products were dried under a vacuum at $60{ }^{\circ} \mathrm{C}$ for $10 \mathrm{~h}$.

2.4. Oxidative Decomposition of Formaldehyde on $\mathbf{K}_{x} \mathrm{M}$ $\mathrm{nO}_{2}$ Nanomaterials. Catalytic activities of as-prepared samples for the oxidation of $\mathrm{HCHO}$ were studied with a fixed-bed quartz flow reactor (length $=300 \mathrm{~mm}$, diameter $=4 \mathrm{~mm}$ ) by passing a gas mixture of $100 \mathrm{ppm} \mathrm{HCHO}, 20 \mathrm{vol} \% \mathrm{O}_{2}$, and the balance gas $(\mathrm{He})$ at a total flow rate of $50 \mathrm{~cm}^{3} \mathrm{~min}^{-1}$ in a space velocity of GHSV $=50000 \mathrm{~h}^{-1} .{ }^{32} \mathrm{~A}$ total of $50 \sim 70 \mathrm{mg}$ of catalysts were loaded. $\mathrm{HCHO}, \mathrm{CO}$, and $\mathrm{CO}_{2}$ were analyzed on-line using a gas chromatograph (GC) equipped with hydrogen flame ionization detector (FID) and Ni catalyst converter which was used for converting carbon oxides and $\mathrm{HCHO}$ quantitatively into methane in the presence of hydrogen before the detector. Separation of reactants and products was achieved using two columns: a carbon molecular sieve column for permanent gases $\left(\mathrm{CO}\right.$ and $\mathrm{CO}_{2}$ ) and a GDX-403 column for $\mathrm{HCHO}$. The $\mathrm{HCHO}$ conversion was determined by the equation

$$
\mathrm{HCHO} \text { conversion }(\%)=\frac{[\mathrm{HCHO}]_{\mathrm{b}}-[\mathrm{HCHO}]}{[\mathrm{HCHO}]_{\mathrm{b}}} \times 100
$$

where $[\mathrm{HCHO}]_{\mathrm{b}}(\mathrm{ppm})$ is the $\mathrm{HCHO}$ concentration without passing over catalyst, $[\mathrm{HCHO}](\mathrm{ppm})$ is the $\mathrm{HCHO}$ concentration after passing over catalyst.

2.5. Characterization. Powder X-ray diffraction (XRD) patterns of as-prepared samples were recorded on a Holand PANalytical X'Pert PRO MPD X-ray diffractometer with $\mathrm{Cu}$ $\mathrm{K} \alpha$ radiation $(\lambda=0.1542 \mathrm{~nm})$ operated at $40 \mathrm{kV}$ and $40 \mathrm{~mA}$. The $2 \theta$ range and recording step were $10 \sim 90^{\circ}$ and $0.03^{\circ}$, respectively. Crystallite sizes were calaulated using the Scherrer equation. For the crystallite size calculation, the (001) reflection of as-synthesized $\mathrm{K}_{x} \mathrm{MnO}_{2}$ at a $2 \theta$ of $12.29^{\circ}$ was used. Scanning electron microscopy (SEM) and energy dispersive spectroscopy (EDS) measurements were carried out on a Hitachi S-4300 field emission scanning electron microscope (FESEM). All of the samples were sputtered with gold before observation. For transmission electron microscopy (TEM), powder samples were added on the carbon-coated copper grids and observed on a JEOL JEM-200CX transmission electron microscope at an acceleration voltage of $150 \mathrm{kV}$. Nitrogen adsorption-desorption measurements were performed on a Quantachrome NOVA 4200e surface area analyzer (measurable diameter range 0.35 200 $\mathrm{nm})$ at $-196{ }^{\circ} \mathrm{C}$ using the volumetric method. The as-prepared $\mathrm{K}_{x} \mathrm{MnO}_{2}$ products were first dried at $150{ }^{\circ} \mathrm{C}$ before analysis. The specific surface area was calculated by the BrunauerEmmett-Teller (BET) method using a linear plot over the range $P / P_{0}=0.04 \sim 0.20$ (six points collected). Pore size distributions were estimated from the adsorption branch of the isotherm by the Barrett, Joyner, and Halenda (BJH) method. Pore volumes were determined from the amount of nitrogen adsorbed at $P / P_{0}$ $=0.98$.

\section{Results and Discussion}

3.1. Crystalline Structures and Elemental Analyses. The phase and crystallographic structure of the products were determined by XRD. Figure 1, panels a and b, shows XRD patterns of honeycomb and hollow nanospheres, respectively. They have similar patterns. Significant XRD peaks recorded at $2 \theta=12.29,24.33,36.60$, and $65.67^{\circ}$ could be well assigned to the (001), (002), (100), and (110) planes of $\mathrm{K}_{x} \mathrm{MnO}_{2}$ with a turbostratic structure. ${ }^{33}$ The d-spacings of these planes were estimated to be $0.718 \mathrm{~nm}(001), 0.366 \mathrm{~nm}(002), 0.246 \mathrm{~nm}$ (100), and $0.142 \mathrm{~nm}$ (110). The increase in intensity of the (100) peak was probably related to scattering from remaining organics. From $2 \theta=12.29^{\circ}$, the interlayer spacing was estimated to be ca. $0.72 \mathrm{~nm}$, in good agreement with the literature. ${ }^{17,33}$ For the particle size estimation, the (001) reflection at $2 \theta=12.29^{\circ}$ was used. Calculation by the Scherrer equation showed that the lamellar structure of $\mathrm{K}_{x} \mathrm{MnO}_{2}$ had a thickness of ca. $8.1 \mathrm{~nm}$. 


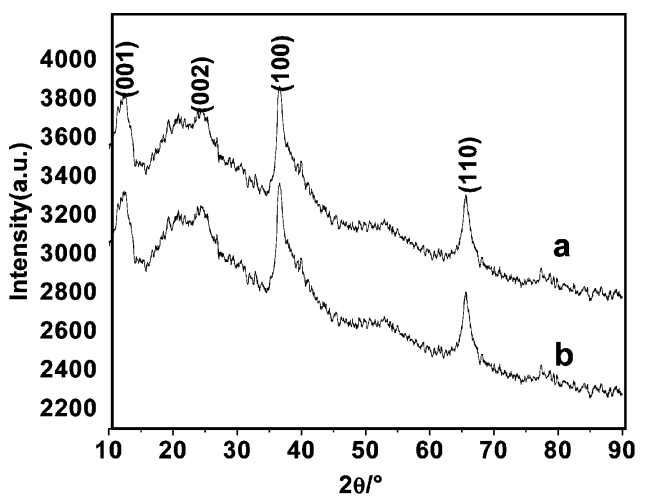

Figure 1. XRD patterns of as-prepared honeycomb (a) and hollow (b) $\mathrm{K}_{x} \mathrm{MnO}_{2}$ nanospheres, respectively.

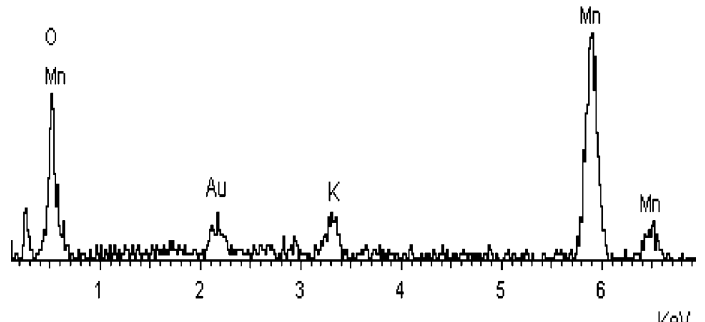

Figure 2. EDS analysis of as-prepared $\mathrm{K}_{x} \mathrm{MnO}_{2}$ nanospheres.

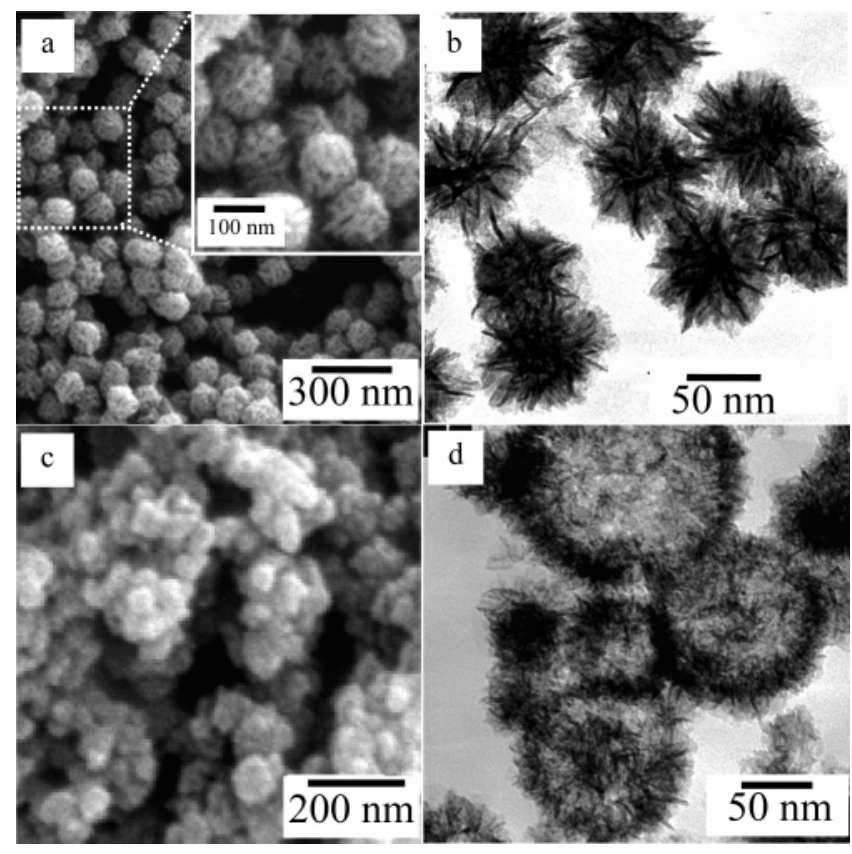

Figure 3. SEM (a) and TEM (b) images of honeycomb $\mathrm{K}_{x} \mathrm{MnO}_{2}$ nanospheres $\left(\mathrm{KMnO}_{4} / \mathrm{OA}=1: 5\right)$ and SEM (c) and TEM (d) images of hollow $\mathrm{K}_{x} \mathrm{MnO}_{2}$ nanospheres $\left(\mathrm{KMnO}_{4} / \mathrm{OA}=1: 1\right)$.

Thus, it is supposed to consist of ca. 7 monolayers. The corresponding EDS results (Figure 2) confirmed the presence of $\mathrm{Mn}, \mathrm{O}$, and $\mathrm{K}$ elements and gave rough atomic ratios of $\mathrm{Mn} / \mathrm{O}$ and $\mathrm{K} / \mathrm{Mn}$ of $1: 2$ and 0.05 , respectively. $\mathrm{K}_{x} \mathrm{MnO}_{2}$ of $x<0.3$ was also reported previously. ${ }^{21}$

3.2. Morphologies of $\mathrm{K}_{x} \mathbf{M n O}_{2}$ Nanospheres. Figure 3a shows a typical SEM image of the product obtained using a $\mathrm{KMnO}_{4} / \mathrm{OA}$ molar ratio of 1:5 after redox reaction for $20 \mathrm{~h}$. Clearly, the product consists of monodisperse nanospheres of ca. $97 \mathrm{~nm}$ in diameter. A magnified image (inset of Figure 3a) shows that the nanosphere in fact has a honeycomb structure that was formed by the self-assembly of nanoplatelets. ${ }^{15}$ The thickness of such platelets was estimated to be ca. $10.7 \mathrm{~nm}$, in

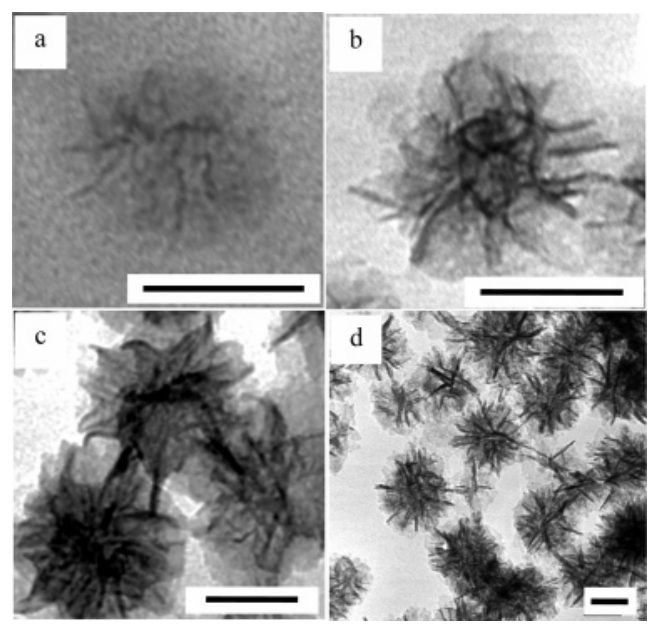

Figure 4. TEM images of honeycomb $\mathrm{KxMnO}_{2}$ nanospheres obtained after redox times of 0.5 (a), 2 (b), 5 (c), and $20 \mathrm{~h}$ (d), respectively. Scale bar: $50 \mathrm{~nm}$.

agreement with the above XRD results. Figure $3 \mathrm{~b}$ shows a typical TEM image of the honeycomb nanospheres. Clearly, each nanosphere consists of platelets that self-align perpendicular to the spherical surface and emanate from the center rather like the structure of a honeycomb. ${ }^{15,34}$ Gray parts are platelets that were vertical to the electron beam, and dark parts are those that were parallel to the electron beam. Figure 3, panels $\mathrm{c}$ and d, shows SEM and TEM images, respectively, of the product obtained using a molar ratio of $\mathrm{KMnO}_{4} / \mathrm{OA}$ at 1:1 after redox reaction for $5 \mathrm{~h}$. The clear contrast between the dark edge and the gray center of each nanosphere (Figure 3d) is evidence of its hollow nature. ${ }^{35}$ A close look at the shells shows that they consist of shorter and thinner platelets than the above honeycomb $\mathrm{K}_{x} \mathrm{MnO}_{2}$ nanospheres. Their size distribution is also not as uniform as that of the latter. It is very interesting that both the honeycomb and hollow $\mathrm{K}_{x} \mathrm{MnO}_{2}$ nanospheres had no changes in morphology upon ultrasonic treatment $(40 \mathrm{kHz}, 120$ $\mathrm{W})$ for $30 \mathrm{~min}$, indicating the robustness of the nanospheres. The validity of the above synthetic approaches on a larger scale was also confirmed by increasing the precursor quantities by 10 fold.

3.3. Evolution of Honeycomb $\mathrm{K}_{x} \mathrm{MnO}_{2}$ Nanospheres with Reaction Time. The size and morphology evolution of honeycomb $\mathrm{K}_{x} \mathrm{MnO}_{2}$ nanospheres were investigated by varying the reaction time. After $0.5 \mathrm{~h}$ of redox reaction, the color of the solution had little changes, and only a small amount of solid was obtained. As shown in Figure 4a, the nanostructure (ca. 50 $\mathrm{nm}$ in size) consisted of nanoplatelets of ca. $2.2 \mathrm{~nm}$ in thickness. The contrast was low, probably because of a small number of nanoplatelets. After $2 \mathrm{~h}$, the color of the solution changed from purple-red to yellow-brown, showing that more $\mathrm{K}_{x} \mathrm{MnO}_{2}$ was formed. As shown in Figure 4b, clear sphere-like nanostructures were formed, in which nanoplatelets self-assembled by standing on each other. The nanostructure and the nanoplatelets were $75 \mathrm{~nm}$ in size and $3.0 \mathrm{~nm}$ in thickness, respectively. With further increase of reaction time, the color of the solution gradually changed to brown-black, and the size of the nanostructure and the thickness of the nanoplatelet increased to nearly 83 and 3.3 $\mathrm{nm}$ (5 h, Figure 4c), 89 and $5.2 \mathrm{~nm}$ (20 h, Figure 4d), respectively. Clearly, the nanoplatelets eventually self-aligned perpendicular to the spherical surface and emanate from the center rather like the structure of a honeycomb (Figure 4d). ${ }^{36}$ Thus, the thickness of the platelet and the size and morphology of nanospheres are dependent on the redox reaction time. ${ }^{37}$ Another interesting observation was that the lamellar platelets 


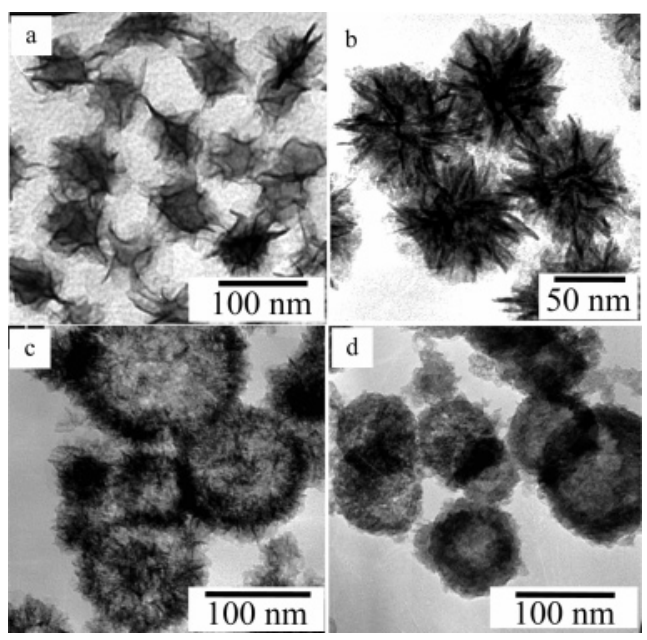

Figure 5. TEM images of $\mathrm{K}_{x} \mathrm{MnO}_{2}$ nanostructures obtained with molar ratios of $\mathrm{KMnO}_{4} / \mathrm{OA}$ of 1:10 (a), 1:5 (b), 1:1 (c), and 2:1 (d), respectively.

initially looked very soft and foldable. In fact, such softness has recently been discussed on the nanometer scale in a review article. $^{38}$

3.4. Effect of the Molar Ratio of $\mathrm{KMnO}_{4} / \mathrm{OA}$ on the Size and Morphology of $\mathrm{K}_{x} \mathbf{M n O}_{2}$ Nanospheres. The effect of the molar ratio of $\mathrm{KMnO}_{4} / \mathrm{OA}$ on the size and morphology of $\mathrm{K}_{x^{-}}$ $\mathrm{MnO}_{2}$ nanospheres was also studied. Figure 5a shows a TEM image of product obtained with a $\mathrm{KMnO}_{4} / \mathrm{OA}$ molar ratio of 1:10. Irregular sphere-like nanostructures with soft and foldable lamellar nanoplatelets were obtained. They were similar in morphology to those nanostructures in Figure 4, panels b and c, which had also been observed in other crystal phases of $\mathrm{MnO}_{2} \cdot{ }^{39}$ At a higher $\mathrm{KMnO}_{4} / \mathrm{OA}$ molar ratio of $1: 5$, honeycomb nanpspheres were obtained, as shown in Figure 5b. Very interesting, hollow nanospheres were produced at a still higher $\mathrm{KMnO}_{4} / \mathrm{OA}$ molar ratio of $1: 1$ (Figure $5 \mathrm{c}$ ). Their shells consisted of loosely packed nanoplatelets and had a thickness of ca. 20 $\mathrm{nm}$. When the molar ratio of $\mathrm{KMnO}_{4} / \mathrm{OA}$ further increased to $2: 1$, hollow nanospheres of denser shells were obtained (Figure $5 \mathrm{~d})$. Therefore, the size and morphology of $\mathrm{K}_{x} \mathrm{MnO}_{2}$ nanospheres are largely dependent on the molar ratio of $\mathrm{KMnO}_{4} / \mathrm{OA}$, and it is possible to tailor the $\mathrm{K}_{x} \mathrm{MnO}_{2}$ nanostructures by adjusting this parameter.

3.5. Formation Mechanism of the Nanostructures. In principle, crystal growth and crystal morphology are determined by the degree of supersaturation, the species to the surface of the crystals, the surface and interfacial energies, and the structure of the crystals. Various extrinsic and intrinsic factors, the crystal structure, and the growth surroundings are accounted for in the final morphology. ${ }^{40}$

Based on the above analysis, a plausible mechanism was proposed and is shown in Scheme 1. Oleic acid can form a stable $\mathrm{O} / \mathrm{W}$ emulsion at appropriate concentrations (process a) ${ }^{41}$ In the emulsion, the "Baeyer test for unsaturation" reaction quickly occurs between $\mathrm{KMnO}_{4}$ and oleic acid at the $\mathrm{O} / \mathrm{W}$ interface and produces $\mathrm{K}_{x} \mathrm{MnO}_{2}$ nuclei there (process b) ${ }^{42} \mathrm{At}$ low $\mathrm{KMnO}_{4}$ concentrations, small amounts of lamellar $\mathrm{K}_{x} \mathrm{MnO}_{2}$ platelets are produced, and thus an unstable shell of loosely packed platelets is formed (process c). Removal of oleic acid and formed cis-diol by ethanol results in collapse of the shell, giving honeycomb nanospheres (process d). In contrast, large amounts of lamellar platelets are produced at high $\mathrm{KMnO}_{4}$ concentrations, and thus a robust shell of densely packed platelets is formed (process e). Therefore, the $\mathrm{K}_{x} \mathrm{MnO}_{2}$ shell is
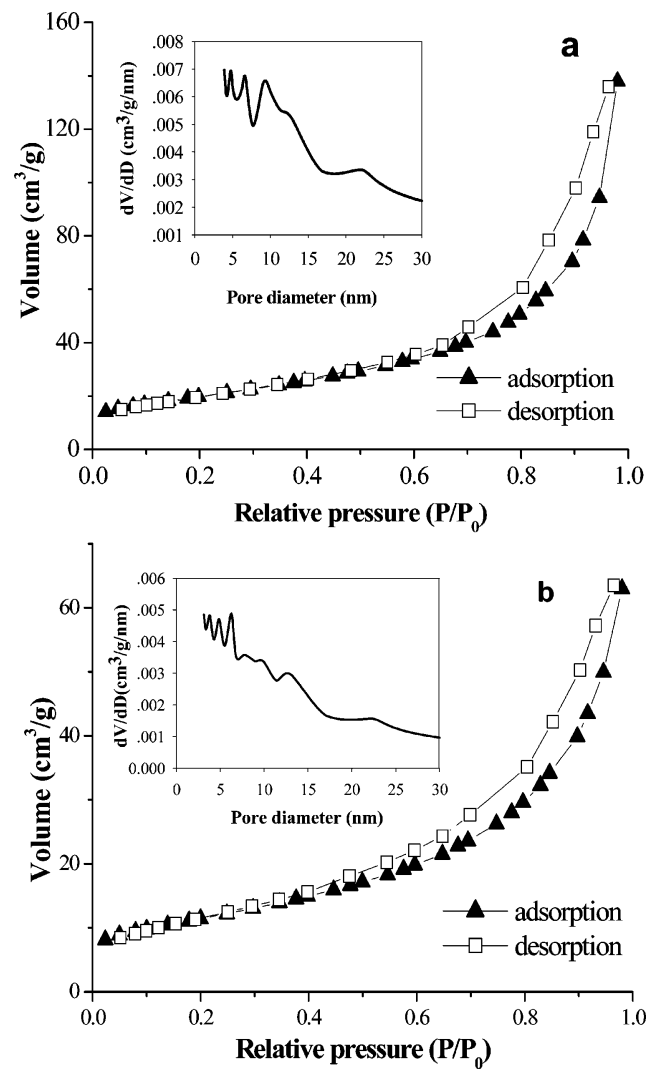

Figure 6. Nitrogen sorption isotherms and pore size distributions (inset) of honeycomb (a) and hollow (b) $\mathrm{K}_{x} \mathrm{MnO}_{2}$ nanospheres.

\section{SCHEME 1: Plausible Formation Mechanism of Honeycomb and Hollow $\mathrm{K}_{x} \mathrm{MnO}_{2}$ Nanospheres}

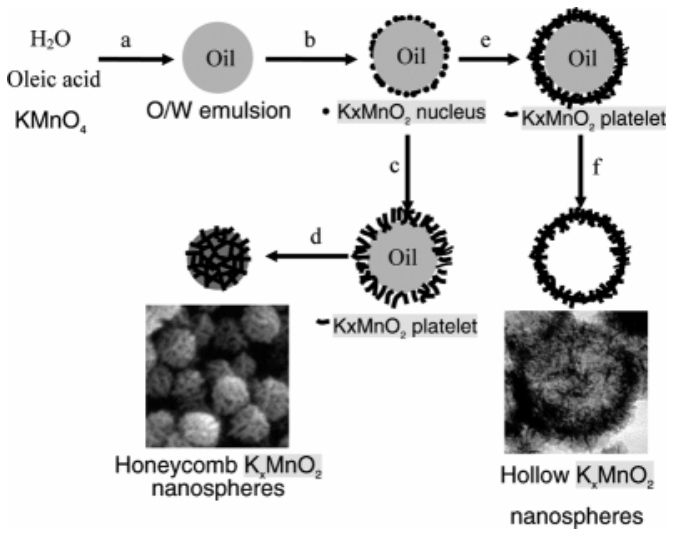

preserved even after removal of oleic acid and formed cis-diol, and hollow nanospheres are formed (process f). Thus, the current approach is believed to be a general method for preparation of metal oxide hollow nanospheres.

3.6. Nitrogen Adsorption-Desorption Measurements. The surface area and pore size distribution of the above nanomaterials were revealed by $\mathrm{N}_{2}$ adsorption-desorption measurements. The results showed that both the honeycomb and hollow nanospheres had a typical type IV adsorption-desorption isotherm with a hysteresis loop characteristic of mesoporous materials based on the IUPAC (Figure 6). ${ }^{43}$ The BET surface areas of the honeycomb and hollow nanospheres were calculated to be 70.70 and $40.69 \mathrm{~m}^{2} / \mathrm{g}$, respectively. The corresponding pore volumes are 0.20 and $0.09 \mathrm{~cm}^{3} / \mathrm{g}$, respectively. As shown by $\mathrm{BJH}$ analyses, the pore size of the honeycomb nanosphere has a tri-modal distribution at 4.9, 6.5, and $9.0 \mathrm{~nm}$ (Figure 6a, inset), and that of the hollow nanosphere has a multi-modal 


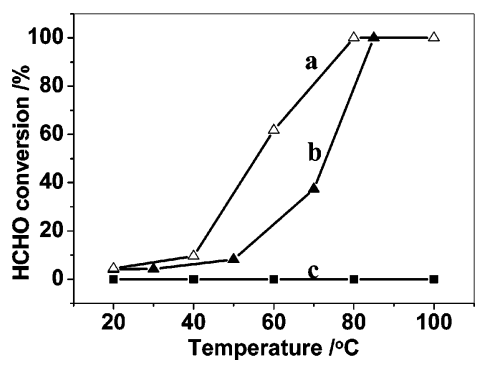

Figure 7. $\mathrm{HCHO}$ conversion on control (ם), honeycomb $\mathrm{K}_{x} \mathrm{MnO}_{2}$ nanospheres $(70 \mathrm{mg})(\boldsymbol{\Delta})$, and hollow $\mathrm{K}_{x} \mathrm{MnO}_{2}$ nanospheres $(50 \mathrm{mg}$ ) $(\triangle)$, respectively.

distribution at 3.7, 4.7, 6.2, and $13.0 \mathrm{~nm}$ (Figure 6b, inset), respectively. The mesopores are attributed to the interstitial space between nanoplatelets of honeycomb and hollow nanostructures. These results agree well with those of XRD, SEM, and TEM measurements. The high BET surface area is beneficial as catalyst or catalyst supports for catalytic reactions.

3.7. Oxidative Decomposition of Formaldehyde on AsSynthesized $\mathbf{K}_{x} \mathbf{M n O}_{2}$ Nanospheres. A sample $(50 \mathrm{mg}$ ) of the hollow $\mathrm{K}_{x} \mathrm{MnO}_{2}$ nanospheres showed the highest catalytic activity for decomposition of $\mathrm{HCHO}$, and at $60{ }^{\circ} \mathrm{C}$, the $\mathrm{HCHO}$ conversion reached $61.8 \%$ (Figure 7 , curve a). A sample (70 $\mathrm{mg}$ ) of the honeycomb nanospheres achieved a HCHO conversion of $24 \%$ at the same temperature (Figure 7, curve b). The $\mathrm{HCHO}$ conversion by the hollow $\mathrm{K}_{x} \mathrm{MnO}_{2}$ nanospheres $(50 \mathrm{mg}$ ) increased to $100 \%$ when the temperature was raised to $80^{\circ} \mathrm{C}$, and that by the honeycomb nanospheres $(70 \mathrm{mg})$ needed $85^{\circ} \mathrm{C}$ to reach a $100 \%$ conversion. In sharp contrast, no $\mathrm{HCHO}$ conversion was noticeable in a control experiment. This is the first report of catalytic decomposition of $\mathrm{HCHO}$ by mesoporous layered $\mathrm{K}_{x} \mathrm{MnO}_{2}$ nanomaterials at such low temperatures.

The catalytic activities of the as-prepared $\mathrm{K}_{x} \mathrm{MnO}_{2}$ nanomaterials were compared with those of previous reported materials. OMS-2 nanorods (200 mg) showed a HCHO conversion of $13 \%$ at $60{ }^{\circ} \mathrm{C}$. It increased to $100 \%$ when the reaction temperature was raised to $80{ }^{\circ} \mathrm{C} .{ }^{29} \mathrm{Mn} 18.2 \mathrm{wt} \% / \mathrm{Al}_{2} \mathrm{O}_{3}$ catalysts $(100 \mathrm{mg})$ had no activity at temperatures lower than $150^{\circ} \mathrm{C}$. The HCHO conversation by these catalysts reached $100 \%$ when reaction temperature was increased to $220{ }^{\circ} \mathrm{C}$. Mn $18.2 \mathrm{wt} \% / \mathrm{Pd} 0.4 \mathrm{wt}$ $\% / \mathrm{Al}_{2} \mathrm{O}_{3}$ catalysts $(100 \mathrm{mg})$ gave a $\mathrm{HCHO}$ conversation of $100 \%$ at temperatures higher than $80{ }^{\circ} \mathrm{C} .{ }^{29}$ Both OMS-2 nanorods $(200 \mathrm{mg})$ and $\mathrm{Mn} 18.2 \mathrm{wt} \% / \mathrm{Pd} 0.4 \mathrm{wt} \% / \mathrm{Al}_{2} \mathrm{O}_{3}(100$ $\mathrm{mg}$ ) catalysts had no catalytic activity when reaction temperature was lower than $50{ }^{\circ} \mathrm{C} .{ }^{29}$ Even though the mesoporous hollow $\mathrm{K}_{x} \mathrm{MnO}_{2}$ nanospheres had a surface area nearly 2 times lower than that of mesoporous honeycomb $\mathrm{K}_{x} \mathrm{MnO}_{2}$ nanospheres, it still showed a much higher catalytic activity for the $\mathrm{HCHO}$ conversion. The HCHO conversion per gram of the hollow $\mathrm{K}_{x^{-}}$ $\mathrm{MnO}_{2}$ nanospheres (Figure 8, curve a) is about 4 times as high as that of the honeycomb $\mathrm{K}_{x} \mathrm{MnO}_{2}$ nanospheres (Figure 8, curve b) at $60{ }^{\circ} \mathrm{C}$ and about 2 times as high as that of the honeycomb $\mathrm{K}_{x} \mathrm{MnO}_{2}$ nanospheres at $80{ }^{\circ} \mathrm{C}$. In contrast, OMS-2 nanorods and $\mathrm{MnO}_{x}$ powders gave a $\mathrm{HCHO}$ conversion per gram of less than 1 at $60{ }^{\circ} \mathrm{C}$ (Figure 8, curve c) and of less than 5 at $80^{\circ} \mathrm{C}$ (Figure 8, curve d). Thus, the catalytic activities of these $\mathrm{MnO}_{2}$ nanomaterials for HCHO oxidation fall in the order of hollow $\mathrm{K}_{x} \mathrm{MnO}_{2}$ nanospheres $>$ honeycomb $\mathrm{K}_{x} \mathrm{MnO}_{2}$ nanospheres $>$ OMS-2 nanorods $>\mathrm{MnO}_{x}$ powders. Clearly, the catalytic activity of $\mathrm{MnO}_{2}$ nanomaterial is largely dependent on its morphology. The hollow $\mathrm{K}_{x} \mathrm{MnO}_{2}$ nanospheres would adsorb and retain $\mathrm{HCHO}$ for a longer period of time than the honeycomb $\mathrm{K}_{x} \mathrm{MnO}_{2}$ nanospheres and eventually enhance the oxidation of $\mathrm{HCHO}$. The smaller size of nanoplatelets in hollow

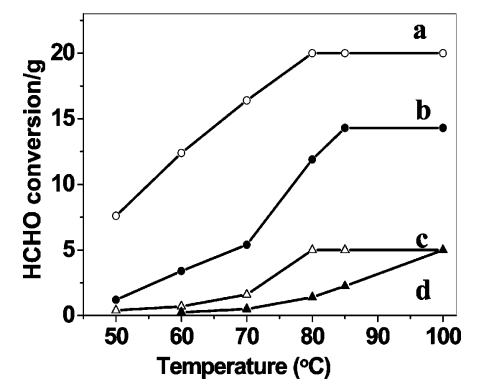

Figure 8. $\mathrm{HCHO}$ conversion per gram of samples on $\mathrm{MnO}_{x}$ powder $(\boldsymbol{\Delta})$, OMS-2 nanorods $(\Delta)$, honeycomb $(\bullet)$ and hollow $(\mathrm{O}) \mathrm{K}_{x} \mathrm{MnO}_{2}$ nanospheres, respectively.

$\mathrm{K}_{x} \mathrm{MnO}_{2}$ nanospheres than in honeycomb $\mathrm{K}_{x} \mathrm{MnO}_{2}$ nanospheres would be another reason for their higher catalytic activity.

\section{Conclusion}

In summary, we developed a facile approach to preparation of mesoporous nanospheres of layered $\mathrm{MnO}_{2}$ at room temperature. It involves a redox reaction of $\mathrm{KMnO}_{4}$ and oleic acid at the $\mathrm{O} / \mathrm{W}$ interface, followed by self-assembly of formed $\mathrm{K}_{x^{-}}$ $\mathrm{MnO}_{2}$ nanoplatelets into $\mathrm{K}_{x} \mathrm{MnO}_{2}$ nanostructures. Both monodisperse honeycomb and hollow $\mathrm{K}_{x} \mathrm{MnO}_{2}$ nanospheres were prepared in high yields depending on the molar ratio of $\mathrm{KMnO}_{4} /$ OA. These new nanomaterials had robust nanostructures and showed morphology-dependent catalytic activities for decomposition of formaldehyde. Complete conversion of $\mathrm{HCHO}$ to $\mathrm{CO}_{2}$ and $\mathrm{H}_{2} \mathrm{O}$ could be achieved at low temperatures, and harmful byproducts were not detected in effluent gases. The catalytic activities were also significantly higher than those of previously reported $\mathrm{MnO}_{2}$ OMS-2 nanorods, $\mathrm{MnO}_{x}$ powders, and $\mathrm{Mn}-\mathrm{Pd} / \mathrm{Al}_{2} \mathrm{O}_{3}$ catalysts. Although $\mathrm{TiO}_{2}$ had no activity for $\mathrm{HCHO}$ oxidation, $\mathrm{TiO}_{2}$-supported noble metals ( $\mathrm{Pt}, \mathrm{Au}, \mathrm{Pd}$, and $\mathrm{Rh}$ ) showed high activities under otherwise identical conditions when the noble metal loading reached a certain quantity. ${ }^{32}$ Palladium also enhanced the activity of $18.2 \mathrm{wt} \% \mathrm{Mn} / \mathrm{Al}_{2} \mathrm{O}_{3}$ catalysts, as discussed above. ${ }^{28,29}$ Thus, the mesoprous $\mathrm{K}_{x} \mathrm{MnO}_{2}$ nanospheres would be convenient and effective catalysts and catalyst supports for noble metals, such as $\mathrm{Pt}, \mathrm{Au}, \mathrm{Pd}$, and Rh. ${ }^{32,44}$ In fact, they are currently being investigated as catalyst supports for noble metal nanaparticles in our laboratory. Such materials are also believed to have applications as adsorbents and separation materials, ${ }^{18}$ and in electrodes, electrolytes, ${ }^{19}$ and electromagnetic and electronic devices. ${ }^{20}$

Acknowledgment. We are grateful to the "Hundred Talents Program" of CAS, the National Basic Research Program of China (Grant No. 2006CB933000), and the National Natural Science Foundation of China (Grant No.20471065) for financial supports.

\section{References and Notes}

(1) (a) Hu, J. T.; Odom, T. W.; Lieber, C. M. Acc. Chem. Res. 1999, 32, 435. (b) Hupp, J. T.; Poeppelmeier, K. R. Science 2005, 309, 2008.

(2) (a) Huang, M. H.; Mao, S.; Feick, H.; Yan, H.; Wu, Y.; Kind, H.; Weber, E.; Russo, R.; Yang, P. Science 2001, 292, 1897. (b) Chen, J.; Xu, L. N.; Li, W. Y.; Gou, X. L. Adv. Mater. 2005, 17, 582.

(3) (a) Tian, Z.; Tong, W.; Wang, W. J.; Duan, N.; Krishnan, V. V.; Suib, S. L. Science 1997, 276, 926. (b) Toberer, E. S.; Seshadri, R. Adv. Mater. 2005, 17, 2244.

(4) (a) Chen, H.; He, J. Chem. Lett. 2007, 36, 174. (b) Mao, Y. B.; Kanungo, M.; Benny, T. H.; Wong, S. S.; J. Phys. Chem. B 2006, 110, 702. (c) Lou, X. W.; Wang, Y.; Yuan, C. L.; Lee, J. Y.; Archer, L. A. Adv. Mater. 2006, 18, 2325. (d) Li, X. H.; Zhang, D. H.; Chen, J. S. J. Am. Chem. Soc. 2006, 128, 8382. (e) Wang, S. T.; Feng, L.; Jiang, L. Adv. 
Mater. 2006, 18, 767. (f) Caruso, F.; Spasova, M.; Susha, A.; Giersig, M.; Caruso, R. A. Chem. Mater. 2001, 13, 109.

(5) Cushing, B. L.; Kolesnichenko, V. L.; O'Connor, C. J. Chem. Rev. 2004, 104, 3893 .

(6) (a) Thackeray, M. M. Prog. Solid State Chem.1997, 25, 1. (b)

Espinal L, Suib S L and Rusling J F. J. Am. Chem. Soc. 2004, 126, 7676.

(7) Armstrong, A. R.; Bruce, P. G. Nature 1996, 381, 499.

(8) Ammundsen, B.; Paulsen, J. Adv. Mater. 2001, 13, 943.

(9) Winter, M.; Brodd, R. J. Chem. Rev. 2004, 104, 4245.

(10) Toupin, M.; Brousse, T.; Bélanger, D. Chem. Mater. 2002, 14, 3946.

(11) Cheng, F. Y.; Zhao, J.; Song, W.; Li, C.; Ma, H.; Chen, J.; Shen, P. Inorg. Chem. 2006, 45, 2038.

(12) Wills, A. S.; Raju, N. P.; Greedan, J. E. Chem. Mater. 1999, 11, 1510 .

(13) (a) Segal, S. R.; Park, S. H.; Suib, S. L. Chem. Mater. 1997, 9, 98 (b) Greedan, J. E.; Raju, N. P.; Wills, A. S.; Morin, C.; Shaw, S. M. Chem. Mater. 1998, 10, 3058 .

(14) Yamamoto, S.; Matsuoka, O.; Fukada, I.; Ashida, Y.; Honda. T.; Yamamotoy, N. J. Catal. 1996, 159, 401.

(15) (a) Yuan, J. K.; Li, W. N.; Gomez, S.; Suib, S. L. J. Am. Chem. Soc. 2005, 127, 14184. (b) Yuan, J.; Laubernds, K.; Zhang, Q.; Suib, S. L. J. Am. Chem. Soc. 2003, 125, 4966.

(16) Li, Z. Q.; Ding, Y.; Xiong, Y. J.; Yang, Q.; Xie, Y. Chem. Commun. 2005, 918 .

(17) (a) Ma, Y.; Luo, J.; Suib, S. L. Chem. Mater. 1999, 11, 1972. (b) Feng, Q.; Kanoh, H.; Ooi, K. J. Mater. Chem. 1999, 9, 319. (c) Golden, D. C.; Chen, C. C.; Dixon, J. B. Clays Clay Miner. 1987, 35, 271.

(18) Lina, A. A.; Dyer, A.; Harjula, R. J. Mater. Chem. 2003, 13, 2963.

(19) Aronson, B. J.; Kinser, A. K.; Passerini, S.; Smyrl, W. H.; Stein,

A. Chem. Mater. 1999, 11, 949.

(20) Nakayama, M.; Konishi, S.; Tagashira, H.; Ogura, K. Langmuir 2005, 21, 354

(21) (a) Mori, S.; Chen, C. H.; Cheonq, S. W. Nature 1998, 392, 473. (b) Ge, J.; Zhuo, L.; Yang, F.; Tang, B.; Wu, L. Z.; Tung, C. J. Phys. Chem. B 2006, 110, 17854

(22) (a) Ahn, M.; Fillry, T. R.; Jafvert, C. T.; Nies, L.; Hua, I.; Cruz, J. Environ. Sci. Technol. 2006, 40, 215. (b) Barrett, K. A.; Mcbride, M. B. Environ. Sci. Technol. 2005, 39, 9223. (c) Sekine, Y. Atmos. Environ. 2002, $36,5543$.

(23) Gaillot, A. C.; Lanson, B.; Drits, V. A. Chem. Mater. 2005, 17, 2959.

(24) Ching, S.; Roark, J. L.; Duan, N.; Suib, S. L. Chem. Mater. 1997, 9,750 3,409

(25) Yang, X.; Tang, W.; Feng, Q.; Ooi, K. Cryst. Growth Des. 2003,

(26) Omomo, Y.; Sasaki, T.; Wang, L.; Watanabe, M. J. Am. Chem. Soc. 2003, 125, 3568

(27) Collins, J. J.; Ness, R.; Tyl, R. W.; Krivanek, N.; Esmen, N. A.; Hall, T. A. Regul. Toxicol. Pharm. 2001, 34, 17.

(28) (a) Alvarez-Galván, M. C.; de la Peña O’Shea, V. A.; Fierro, J. L.

G.; Arias, P. L. Catal. Commun. 2003, 4, 223. (b) Imamura, S.; Uchihori,

D.; Utani, K. Catal. Lett. 2004, 24, 377.

(29) (a) Tang, X. F.; Huang, X. M.; Shao, J. J.; Liu, J. L.; Li, Y. G.;

Xu, Y. D.; Shen, W. J. Chin. J. Catal. 2006, 27, 97. (b) Álvarez-Galván,

M. C.; Pawelec, B.; de la Peña, O’Shea, V. A.; Fierro, J. L. G.; Arias, P.

L. Appl. Catal. B: Environ. 2004, 51,83.

(30) Sinha, A. K.; Suzuki, K.; Takahara, M.; Azuma, H.; Nonaka, T.; Fukumoto, K. Angew. Chem., Int. Ed. 2007, 46, 2891.

(31) Fessenden, R. J.; Fessenden, J. S. Organic Chemistry; Willard Grant Press: Boston, MA, 1979; p 413.

(32) (a) Zhang, C.; He, H.; Tanaka, K. Catal. Commun. 2005, 6, 211

(b) Zhang, C.; He, H.; Tanaka, K. Appl. Catal. B: Environ. 2006, 65, 37.

(33) (a) Villalobos, M.; Lanson, B.; Manceau, A.; Toner, B.; Sposito,

G. Am. Miner. 2006, 91, 489. (b) Drits, V. A.; Silvester, E.; Gorshov, A

I.; Manceau, A. Am. Miner. 1997, 82, 946.

(34) (a) Zhong, L.; Hu, J.; Liang, H.; Cao, A.; Song, W.; Wan, L. Adv Mater. 2006, 18, 2426. (b) Liu, B.; Zeng, H. C. J. Am. Chem. Soc. 2004, $126,8124$.

(35) Caruso, F.; Caruso, R. A.; Möhwald, H. Science 1998, 282, 1111.

(36) (a) Wang, D.; Song, C.; Hu, Z.; Fu, X. J. Phys. Chem. B 2005 109, 1125. (b) Cao, A.; Hu, J.; Liang, H.; Wan, L. Angew. Chem., Int. Ed. 2005, 44, 4391.

(37) Lameiras, F. S. Mater. Res. 1999, 2, 139

(38) He, J.; Kunitake, T. Soft Matter 2006, 2, 119.

(39) Wu, C.; Xie, Y.; Wang, D.; Yang, J.; Li, T. J. Phys. Chem. B 2006 $107,13583$.

(40) Wang, X. L.; Yan, C. L.; Zou, L. J.; Xue, D. F. Inter. J. Nanosci 2006, 5, 219.

(41) Cheng, X.; Liu, S.; Lu, L.; Sui, X.; Meynen, V.; Cool, P.; Vansant, E. F.; Jiang, J. Microporous Mesoporous Mater. 2006, 98, 41.

(42) Huang, J.; Xie, Y.; Li, B.; Liu, Y.; Qian, Y.; Zhang, S. Adv. Mater. 2000, 12, 808 .

(43) Sing, K. S. W.; Everett, D. H.; Haul, R. A. W.; Moscou, L.; Piertti,

R. A.; Rouquèrol, J.; Siemieniewska, T. Pure Appl. Chem. 1985, 57, 603.

(44) Cellier, C.; Ruaux, V.; Lahousse, C.; Grange, P.; Gaigneaux, E. M. Catal. Today 2006, 117, 350 